\title{
A AMPLITUDE CONSTITUCIONAL DA CARTA DAS NAÇÕES UNIDAS: CONTROVÉRSIAS DE UMA PROPOSTA DE CONSTITUIÇÃO PARA A COMUNIDADE INTERNACIONAL
}

\section{RESUMO}

${ }^{1}$ Maury Roberto Viviani

Este artigo objetiva examinar a dimensão da concepção teórica que erige a Carta da ONU como uma constituição da comunidade internacional. A metodologia segue o percurso indutivo, com base em referencial bibliográfico. Apresenta esboço conceitual e categorizador do constitucionalismo global, discute a ideia de comunidade internacional, identifica características constitucionais da Carta da ONU. Conclui que a Carta da ONU representa mais que um tratado, mas suas limitadas virtudes constitucionais, a ausência dos elementos que configurem tradicionalmente uma constituição, as deficiências institucionais e a realidade das relações internacionais não a legitimam como uma constituição abrangente da comunidade internacional.

Palavras-chave: Carta das nações unidas, Constituição, Comunidade internacional, Constitucionalismo global

\section{LA AMPLITUD CONSTITUCIONAL DE LA CARTA DE LAS NACIONES UNIDAS: CONTROVERSIAS DE UNA PROPUESTA DE CONSTITUCIÓN PARA LA COMUNIDAD INTERNACIONAL}

\section{RESUMEN}

Este artículo busca examinar la amplitud del concepto que considera la Carta de la ONU una constitución de la comunidad internacional. La metodología sigue la ruta inductiva, basada en referencias bibliográficas. Presenta esquema conceptual y categorizador del constitucionalismo global, discute la idea de comunidad internacional y identifica las características constitucionales de la Carta. Concluye que la Carta es más que un tratado, pero sus virtudes constitucionales limitadas, la ausencia de los elementos que tradicionalmente conforman una constitución, las deficiencias institucionales y la realidad de las relaciones internacionales no permiten su reconocimiento como una constitución amplia de la comunidad internacional.

Palabras-claves: Carta de las naciones unidas, Constitución, Comunidad internacional, Constitucionalismo global

\footnotetext{
1 Doutor em Direito, por Convênio de Dupla Titulação, pela Università degli Studi di Perugia - Itália. Professor da Universidade do Vale do Itália, e da Escola do Ministério Público de Santa Catarina, Brasil.

E-mail: mauryrv@hotmail.com (Brasil).
} 


\section{INTRODUÇÃO}

Ao se valer de características que possam revestir a Carta das Nações Unidas de um perfil constitucional, este artigo tem como objetivo discutir qual a dimensão da concepção teórica que atribui a este documento a qualidade de uma "constituição da comunidade internacional" e, mais especificamente, avaliar em que sentido se pode dar acolhida ao interesse e à contribuição política e acadêmica dessa proposta.

Seria uma mera abstração acadêmica cogitar que a Carta das Nações Unidas corresponderia a uma forma de materialização global de uma ordem constitucional direcionada a toda a comunidade internacional? Qual a real possibilidade dessa convicção? Em que medida pode ser compreendida a sua dimensão?

A exploração desta problematização situa-se no âmbito de estudo do "constitucionalismo global", como uma de suas vertentes, que se erige como tema central relacionado à preocupação de se dar uma resposta jurídica à intensificação da globalização, concomitantemente com o esforço da organização e da governança para além do Estado, ou seja, da constitucionalização na esfera internacional. Dito de outra maneira, esse ramo investigatório insere-se na linha de reflexão que busca na linguagem do constitucionalismo encontrar soluções adequadas à governança e ao direito no âmbito global.

$\mathrm{Na}$ oportunidade na qual expôs suas reflexões por ocasião da publicação de obra comemorativa aos 50 anos da Organização das Nações Unidas, Tomuschat (1995, p. ix) já expressava a convicção de que a Carta das Nações Unidas, como um texto fundamental da ordem mundial, se revestiria da qualidade de uma "constituição da comunidade internacional", muito embora não desconhecesse as dificuldades para que possa ser reconhecida como uma constituição mundial ou global. Ante a importância acadêmica, a estruturação teórica dessa vertente pode ser identificada, dentre outros trabalhos, nas abordagens de Dupuy (1997), Macdonald (2005) e Fassbender (2009).

A atribuição de caráter constitucional à Carta das Nações Unidas, sem desconsiderar que se trata de uma ideação de dimensão polêmica, suscita uma ordem de indagações que acompanha os temas indissociáveis da intensa internacionalização e da complexidade do direito no cenário contemporâneo, ambientado nos desafios da própria evolução do direito internacional, notadamente no seu desenvolvimento no período posterior à Segunda Guerra Mundial e, agora com mais ênfase, no limiar do século XXI. 
O tema aventado pode colher sua justificação em razão de alguns fenômenos destacados, tais como as intensas transformações sociais, econômicas, culturais e jurídicas que se dinamizam na atualidade e ocasionam rupturas paradigmáticas que, além das perplexidades inerentes às sensações que originam, desafiam os tradicionais modelos de organização social. Mais recentemente, algumas abordagens acadêmicas recepcionaram a perspectiva, sempre criticada, do desenvolvimento de uma nova ordem mundial.

Em tal cenário, a realidade contemporânea permite que possam ser reavaliadas as noções de soberania estatal, de constituição e de direito, notadamente em razão da intensificação da sociedade mundial e do consequente processo de globalização. Além da demarcação entre os âmbitos interno (estatal) e externo (internacional) já não ser tão evidente, os Estados passaram a estabelecer organizações internacionais às quais transferiram parte de suas atribuições soberanas (GRIMM, 2012, p. 9-10).

O estudo a respeito de uma ordem internacional constitucionalizada também pode encontrar justificativa na busca de compreensão do problema da soberania e do papel dos Estados no mundo contemporâneo, do crescimento no número de atores na esfera pública internacional, da proliferação das fontes normativas e das instâncias decisórias internacionais, das normas de efeito erga omnes e jus cogens, da necessidade de cooperação transnacional, dos desafios dos assuntos de amplitude global e, até mesmo, em face da fragmentação do direito internacional. Nessas condições, a abordagem pode servir de reflexão ao enfrentamento dos problemas comuns do mundo globalizado que transcendem as fronteiras estatais, como o meio ambiente, a paz, a universalização do mercado e do consumo, o desenvolvimento tecnológico e cibernético, os fluxos migratórios, e os demais temas relacionados ao alargamento dos ambientes econômico e social.

Se o cenário pode indicar caminhos fragmentados, Weller (2009, p. 180) argumenta que essas tendências desintegradoras seriam contrabalançadas pelo desenvolvimento do sistema internacional que se opera desde o ano de 1945, que autoriza a diversos acadêmicos sustentarem que estaríamos sendo direcionados para um sistema constitucional internacional com base em valores comuns, na rule of law internacional e em mecanismos para a aplicação da lei (law enforcement).

Parece necessário reconhecer, entretanto, que a noção de constitucionalismo, com suas correlatas conquistas históricas, tais como os princípios da rule of law, da separação dos poderes, do sistema de freios e contrapesos (check and balances), da proteção de direitos fundamentais e da democracia, evoca uma íntima e simbólica relação com a esfera circunscrita aos limites jurídico-políticos da soberania do Estado.

De tal maneira, conceber a utilização, na esfera internacional/global, de aportes 
constitucionais típicos e inerentes à organização estatal, costuma apresentar-se, pelo menos num primeiro momento, como uma perspectiva problemática, especialmente porque coloca em evidência duas distintas vertentes de análise: por um lado, a visão particularista, para a qual uma ordem global seria uma idealização com escassa possibilidade de realização, e, de outro lado, a abordagem universalista, em que uma ordem baseada numa rede de cooperação seria viável e corresponderia às necessidades contemporâneas em torno de valores comuns da comunidade internacional.

Essa visão dicotômica pode ser ampliada para um universo de estudo e observação multifacetado, em que outras óticas compõem e contribuem para o debate acadêmico contemporâneo relacionado à compreensão do constitucionalismo para além dos Estados.

A metodologia da pesquisa empregada para a consecução do artigo segue o método indutivo, com base em exploração bibliográfica. Para as referências será utilizado o sistema autor-data. As citações e paráfrases de textos em línguas estrangeiras são de nossa livre tradução, razão pela qual não dispensam a consulta aos originais, devidamente referenciados. $\mathrm{O}$ relato e a interpretação do material abordado serão apresentados analiticamente nas considerações finais.

Para se explorar a discussão do tema proposto, a estrutura do artigo se articula por intermédio de três objetivos específicos. Inicialmente, além de uma aproximação conceitual, almeja-se apresentar uma categorização das diversas escolas que tratam do debate atual a respeito do "constitucionalismo global". Na sequência, objetiva-se estabelecer aportes que permitam compreender a ideia de comunidade internacional, considerando que consiste numa categoria interligada à finalidade do artigo. A abordagem culminará com a identificação das principais características constitucionais da Carta das Nações Unidas e dos consequentes argumentos que eventualmente possam se constituir como resistência à aceitação da perspectiva que lhe atribui o locus de constituição da comunidade internacional, de forma que o conjunto dos argumentos examinados permita, ao final, examinar o alcance da proposta.

\section{DELINEAMENTO CONCEITUAL E CATEGORIZAÇÃO DO DEBATE A PROPÓSITO DO CONSTITUCIONALISMO GLOBAL}

A delimitação conceitual da expressão constitucionalismo global não pode desconhecer que as significações apresentam-se em múltiplas roupagens, identificadas com as diversas escolas ou concepções teóricas que procuram compreender e buscar respostas adequadas ao enfrentamento da intensificação da sociedade mundial em face da globalização e das transformações que se operam no sistema internacional, cujo paradigma, na já 
desgastada concepção westfaliana de Estado, aparenta estar em processo de mudança.

Prefere-se, nesta abordagem, o termo constitucionalismo global, embora se possa entendê-lo como sinônimo de constitucionalismo internacional, que guarda um destacado referencial histórico no período do entre guerras do século passado, com a publicação, em 1926, da obra Die Verfassung der Völkerrechtsgemeinshaft (The Constitution of the International Legal Community), pelo austríaco Alfred Verdross.

O contexto histórico, político e social dessa referência inaugural, no entanto, não era o mesmo que se apresenta na atualidade, daí porque se trata tema de interesse renovado. De fato, conforme enfatiza Peters (2015, p. 12-13), desde os anos 1990, destacados autores da escola germânica deram início ao debate contemporâneo a respeito do constitucionalismo para além do Estado. Esses estudos partem da concepção de que, por um lado, desenvolve-se uma erosão do princípio do consentimento (consequentemente, da soberania dos Estados) e que, por outro lado, estaria emergindo, concretamente, uma comunidade internacional.

Inicialmente, para se estabelecer um conceito operacional que permita avançar no problema, há que se permitir uma interpretação que aceite a premissa de que uma constituição não se circunscreve ao âmbito dos Estados tal qual a que culmina dos movimentos dos séculos XVIII e XIX, em que se estabeleceram os limites do poder e a proteção dos direitos fundamentais dos cidadãos. Portanto, além deste sentido estrito, refere-se de maneira geral a qualquer instrumento que constitua uma organização, uma sociedade, mas também um Estado. Para De Wet (2006, p. 53), corresponde a um "sistema em que os diferentes regimes constitucionais nacionais, regionais e funcionais (setoriais) formam os alicerces da comunidade internacional (comunidade política internacional) sustentada por valores comuns". Contudo, é verdade que para o exame da dimensão constitucional da Carta da ONU não se pode evitar que sejam buscadas relações com o modelo tradicional estatal, pois desta esfera é que se verifica a presença dos elementos constitucionais típicos. Consequentemente, este aspecto será uma das dificuldades a se enfrentar, já que a exploração temática do constitucionalismo global costuma provocar o exame das analogias com as constituições domésticas.

No sentido amplo da significação, pode-se então estabelecer um conceito geral para o constitucionalismo global (ou internacional), tal como propõe Peters (2010, p. 214), no sentido de que consiste na perspectiva (tanto acadêmica quanto política), em que se identifica e se defende a aplicação de princípios de matriz constitucional na esfera internacional, tais como o estado de direito, check and balances, direitos humanos e democracia, objetivando ampliar ou melhorar a efetividade e a justiça da ordem jurídica internacional. Adnato a este significado, Peters (2009, p. 397) oferece para a expressão "constitucionalização global" a 
identificação como um processo que se desenvolve de maneira contínua, embora não linearmente, a "gradual emergência e deliberada criação de elementos constitucionais na ordem jurídica internacional por atores políticos e jurídicos, complementados por um discurso no qual esses elementos são identificados e desenvolvidos".

A percepção do constitucionalismo global se desenvolve num complexo e heterogêneo plano de abordagens. Conforme Kleinlein (2012, p. 394), podem acentuar atributos formais ou substantivos, e mesmo características como a supremacia de distintas classes normativas, como jus cogens, obrigações erga omnes, a Carta da ONU, ou ainda os direitos humanos. De uma maneira geral, contudo, o constitucionalismo global pode ser percebido sob o enfoque em que a constitucionalização ocorreria de forma abrangente e unitária, ou sob o enfoque pluralístico, em uma série reunida de processos diferenciados.

Se a gama de abordagens na literatura internacionalista especializada é diversificada, um amplo e competente estudo foi realizado por Schwöbel (2011), a partir da identificação de certas características, de forma a apresentar uma categorização do debate a partir da proposição de quatro dimensões do constitucionalismo global.

Na dimensão que denomina de "constitucionalismo social”, Schwöbel (2011, p. 4243) insere as abordagens cuja ênfase é na coexistência e na limitação do poder por intermédio da participação na sociedade internacional (Estados, organizações não governamentais, indivíduos). Conforme Schwöbel (2011, p. 21), as categorias centrais dessa abordagem são a limitação do poder, a governança, os direitos dos indivíduos e o idealismo social. Essa dimensão comporta duas perspectivas: uma delas denominada de "escola da comunidade internacional", cujos pontos de vista podem se referir desde um sistema constitucional baseado na Carta da ONU (Bardo Fassbender) como a um sistema jurídico internacional baseado em normas peremptórias (Christian Tomuschat); a outra perspectiva desta dimensão corresponde à vertente da "sociedade civil global", que abrangem abordagens como a de Gunther Teubner, de Andréas Fischer-Lescano e de Philip Allot. De uma maneira geral, a ótica da "sociedade civil global" enfatiza a participação dos indivíduos na esfera internacional, em que "os rótulos políticos que fornecem tais formas de participação com legitimação são a 'sociedade civil' (Teubner e Fischer-Lescano) e a 'sociedade internacional' (Allot)".

Quanto à dimensão do “constitucionalismo institucional” (SCHWÖBEL, 2011, p. 2135), as correntes de pensamento são observadas em três tipos distintos: o primeiro baseia-se numa ordem constitucional da governança global, embora afastando a necessidade de uma constituição global e abrangente. Pelo contrário, esse tipo relaciona-se com a ideia de constituição de forma multifacetada e de camadas múltiplas; o segundo tipo identifica-se com 
a proposta que reconhece a Carta da ONU como uma constituição global, material e

formalmente; o terceiro tipo considera a Organização do Comércio Internacional (OMC) e a Organização Internacional do Trabalho (OIT) exemplos de microconstitucionalismo destinados a se constituírem em macroconstitucionalismo. A dimensão do "constitucionalismo institucional" identifica-se com a limitação e a institucionalização do poder, de forma que se preocupa com as questões atinentes ao controle (accountability), a participação e a representação.

O "constitucionalismo normativo", segundo Schwöbel (2011, p. 35-43), consiste na perspectiva que busca uma estrutura de cunho moral para uma ordem global, cujos temaschave (limitação do poder, institucionalização do poder, idealismo, estabelecimento de diretrizes (standard-seting), proteção dos direitos individuais) se identificam, pelos autores que advogam os aspectos próprios dessa dimensão normativa como direito mundial, normas fundamentais e hierarquia normativa ou jus cogens. No âmbito desta dimensão, embora as abordagens se apresentem diversas dependendo da particularidade de cada autor, compartilham o entendimento de que o constitucionalismo global se baseia em "normas universais", tais como "normas de interesse público", "normas fundamentais" ou "normas da comunidade internacional".

Por fim, a dimensão do "constitucionalismo analógico" comporta as perspectivas acadêmicas que buscam no constitucionalismo doméstico e de sistemas jurídicos regionais analogias para aplicação na esfera internacional (SCHWÖBEL, 2011, p. 43-48). Aqui, nesta dimensão, pode ser observado o desenvolvimento do constitucionalismo para além das fronteiras estatais o caso da Europa.

Pois bem, com esta síntese elaborada a partir da classificação de Schwöbel, observase que do panorama que abrange as diferenciadas abordagens a respeito do constitucionalismo global, pode-se verificar que a análise quanto a Carta da ONU se situa nas dimensões do "constitucionalismo social" e do "constitucionalismo institucional", mas de certa forma também identificado com o "constitucionalismo normativo". De todo modo, como adverte a referida autora, não se pode compreender que as divisões apresentadas são estanques, pois as características de cada dimensão sobrepõem-se e interagem. Essa categorização, no entanto, possui o indisfarçável mérito de organizar racionalmente as principais abordagens acadêmicas que tratam do constitucionalismo global, de forma a auxiliar a análise bem como instrumentalizar o pesquisador na distinção própria de cada perspectiva, inclusive no aspecto ideológico.

Para evitar as tentações idealistas que o tema dessa magnitude naturalmente imprime, tem-se como oportuna a advertência de Koskenniemi (2005, p. 616): “As virtudes e os vícios 
do direito internacional não podem ser discutidos em abstrato”.

\section{ARGUMENTAÇÃO APROXIMATIVA DA CONCEPÇÃO QUE IDENTIFICA UMA "COMUNIDADE INTERNACIONAL"}

Afinal, pretendendo-se examinar a abordagem que advoga que a Carta da ONU configura uma "constituição da comunidade internacional", o que de fato se pode entender por uma "comunidade internacional"?

Aliás, a importância de uma aproximação dessa concepção para o presente estudo pode ser aliada ao fato de que, numa das perspectivas de estudo do constitucionalismo global, pode-se identificar a denominada "doutrina da comunidade internacional", que teve surgimento no período que antecedeu a "guerra fria", mas pode ser observada a partir das aulas proferidas por Hermann Mosler, no ano de 1974, em Haia. Representada pelo grupo de acadêmicos cujos expoentes, além Mosler, são Bruno Simma e Christian Tomuschat, trata-se um conjunto de abordagens que constitui a maior influência e repercussão sobre o tema, especialmente na Europa continental (FASSBENDER, 2011, p. 28).

É corriqueira, tanto na esfera acadêmica como na linguagem comum da mídia e de boa parte da população mundial, a utilização da expressão "comunidade internacional”, por mais nebulosa que a sua conceituação e a sua expressão na realidade possam ser aferidas. Sem embargo da imprecisão que essa concepção possa denotar, o termo aparece de forma recorrente em diversos textos de expressão internacional. Como exemplo desse sentido, o art. 53 da Convenção de Viena sobre o Direito dos Tratados menciona que "[...] uma norma imperativa de direito internacional geral é uma norma aceita e reconhecida pela comunidade internacional dos Estados no seu todo [...]", cujo enunciado também foi mantido na Convenção de 1986. Igualmente, o Estatuto de Roma, que estabelece o Tribunal Penal Internacional, traz menções à "comunidade internacional", tanto no Preâmbulo como no artigo quinto. Tal expressão também encontra uso do Tribunal Internacional de Haia. No caso paradigmático Barcelona Traction, em 1970, a Corte, em decisão que protege bens jurídicos específicos, afirmou a diferenciação entre aqueles que transbordam para uma "comunidade internacional" (ex.: proibição de genocídio, escravidão, etc.). daqueles que se referem somente aos Estados. Da mesma forma, em determinadas situações, a Assembleia Geral da ONU se pronuncia com apelos e exortações à "comunidade internacional". Tais menções são encontradas também no Conselho de Segurança. No entanto, é claro que a comunidade internacional precisa de real factualidade, e não apenas depender de textos jurídicos oficiais, como observa Tomuschat (2010, p. 118). 
É oportuno lembrar, na esteira dessa temática, da célebre obra Gemeinschaft um Gesellschaft (Community and Society), publicada em 1887 por Ferdinand Tönnies, que estabelecia uma diferenciação conceitual entre comunidade e sociedade a qual costuma ainda ser aventada nos debates atuais. Para Tönnies (2002), a comunidade importa numa natural relação emocional ou de afeto entre os membros, ou seja, um vínculo entre um número razoável de pessoas. Consequentemente, preocupava-se com os conflitos (político, jurídico econômico, familiar, religioso e cultural) com os reflexos das modificações, principalmente pela crescente modernização dos espaços urbanos, que afetavam as pequenas comunidades, em que os membros compartilham certos valores de vida, ao passo que a sociedade que se forma em larga escala, de mercado e de competição. É bem verdade que, nem comunidade, nem sociedade, se apresentam de forma pura, razão pela qual essa diferenciação deve ser observada com prudência.

Sem embargo das ambiguidades operacionais da mencionada categoria, sugere-se, no entanto, a adoção do entendimento que compreenda a "comunidade internacional" como aquela que reúne um conjunto de atores, tais como as organizações internacionais, as organizações não governamentais, as corporações transnacionais, os Estados, bem como os indivíduos. Se há dificuldades em se admitir um vínculo ideal puro, ou mesmo uma identidade cosmopolita entre todos, "vislumbra-se o desenvolvimento das relações plurilateriais em torno de determinados valores que permitem ser compartilhados para o fim de aperfeiçoar uma 'comunidade internacional'.” (VIVIANI, 2014, p. 207).

Percebendo a possibilidade de contrabalançar a fragmentação do direito internacional, em que setores determinados se diferenciam em lógicas distintas (direitos humanos, meio ambiente, comércio internacional, direito internacional criminal, etc.), Cassese (2005, p. 45) entende que cada uma dessas áreas influencia as demais, de modo que a gradual interpenetração e fertilização cruzada (cross-fertilization), aliada a disseminação dos direitos humanos entre variados setores, permite a integração da comunidade internacional.

Ante todas as controvérsias em torno da real existência de uma verdadeira comunidade internacional, Tomuschat (2010, p. 119) aponta que a interdependência entre os Estados e os povos, o anacronismo do modelo de soberania estatal, o fato de que o planeta terra é "a pátria de todos os homens", são fatores que exigem uma atuação recíproca, baseada em "valores fundamentais comuns", de maneira que "cabría aventurar la prognosis de que en la redefinición del ordenamiento jurídico internacional tendrá cada vez más fuerza la perspectiva que parte de la idea de la Comunidad internacional". 


\section{DIMENSIONAMENTO DO PERFIL CONSTITUCIONAL DA CARTA DAS NAÇÕES UNIDAS: LIMITES E DESAFIOS AO RECONHECIMENTO DE UMA CONSTITUIÇÃO PARA A COMUNIDADE INTERNACIONAL}

Em que consistem as principais qualidades constitucionais da Carta das Nações Unidas que possam lhe conceder o locus de constituição da comunidade internacional? quais os eventuais argumentos que são capazes de obstaculizar a aceitação de tal perspectiva?

Inicialmente, é necessário deixar evidente a elevada missão conferida à Organização das Nações Unidas, desde sua fundação em 24 de outubro de 1945 na cidade de São Francisco (EUA), destinada à consecução da paz e da segurança mundial como esperança em face das sucessivas tragédias bélicas ocasionadas pelo advento da Primeira e da Segunda Grandes Guerras Mundiais. Ademais, reconhece-se o papel desempenhado, por intermédio de seus órgãos e agências, na disseminação e proteção dos direitos humanos e da democracia, no seu papel diante do processo de descolonização, bem como para o fomento do direito internacional. De fato, ante os objetivos e princípios reitores delineados nos enunciados dos

Arts. $1^{\circ}$ e $2^{\circ}$ da sua Carta instituidora, atingindo as mais diversas áreas que importam para a convivência humana (paz, segurança, cooperação internacional, igualdade, direitos humanos, resolução de problemas de caráter econômico, social, cultural ou humanitário, etc.), trata-se de organização internacional que se configura num locus privilegiado e facilitador para a consecução de valores comuns que comportam a essência da dignidade humana. Conforme Kim (1993, p. 57), considerando o fato de que as Nações Unidas são uma organização internacional que se constitui num sistema que congrega uma interação contínua com o fluxo de "megatendêcias globais", praticamente todos os esforços para o constitucionalismo global na era do pós-guerra utilizam sua Carta como "ponto de partida".

Para Habermas (2008, p. 160-161), a Carta da ONU não teria o condão de uma constituição global, sem embargo de reconhecer que por uma interpretação ampliada possa se cogitar essa leitura. De todo modo, entende que reúne aspectos que a tornariam mais aperfeiçoada constitucionalmente do que o antigo estatuto da Liga das Nações, tais como por garantir a paz por intermédio dos direitos humanos, pela proibição do uso da força com a previsão de sanções e ante o seu caráter includente (universalização).

Para explorar o caráter constitucional da Carta da ONU, seguindo-se a análise de Dupuy (1997), há que se tomar o sentido material (substancial), que corresponde a um conjunto de princípios hierárquicos endereçados à comunidade internacional, bem como o sentido institucional (orgânico), em que se observa a identificação dos órgãos, a separação de poderes e a organização da competência das instituições. Com essa dúplice abordagem, o 
sentido material (Arts. $1^{\circ}$ e $2^{\circ}$ da Carta) destina-se a confrontar os princípios enunciados com as normas de caráter jus cogens, enquanto que o sentido formal verifica a eficiência instrumental para garantir a efetivação do conteúdo substancial, com análise que compreende as atividades da Corte Internacional de Justiça e do Conselho de Segurança das Nações Unidas.

No sentido material (substancial), Dupuy (1997, p. 6-7) conclui que as "normas constitucionais" enunciadas na Carta da ONU possuem relação com algumas das mais importantes normas do direito internacional consuetudinário e outras normas de caráter peremptório. Embora não seja completa, como "matriz ética e jurídica", a Carta constitui-se num link com as demais, passíveis de serem peremptórias. ${ }^{1}$ No sentido institucional

\footnotetext{
' Cassese (2012, p. 158) ressalta o papel das cortes para a determinação de existência de uma norma peremptória. Quanto ao surgimento de norma com esta qualidade, enfatiza a importância da aceitação pela comunidade mundial de uma regra consuetudinária como sendo peremptória. Destaca que a maneira mais eficaz para se tornar operacional o caráter jus cogens de uma norma seria os Estados empreenderem esforços para que elas sejam vinculativas no âmbito interno, inclusive suplantando a legislação que a contrarie.
}

(orgânico), Dupuy (1997, p. 19-30 e 32) ressalta o papel do Conselho de Segurança diante da interpretação do Capítulo VII da Carta, especialmente no que concerne ao conceito de “ameaça à paz”, tarefa para a qual tal órgão tem importante responsabilidade. De todo modo, ressalta que ante a fragilidade da legitimidade do Conselho de Segurança, torna-se necessário pensar em uma reformulação buscando maior representatividade e distribuição de poder no âmbito das demais nações. Mesmo ante as dificuldades jurídicas e políticas, Dupuy (1997, p. 33) considera que se tratando de um ambicioso projeto de cooperação entre as nações, a Carta da ONU “é ao mesmo tempo o convênio básico da comunidade internacional e a constituição mundial, já realizada e ainda por vir".

Uma das mais importantes influências acadêmicas na avaliação do alcance constitucional da Carta da ONU pode ser encontrada na abordagem de Fassbender (2009) que, em analogia com o tipo ideal proposto por Max Weber quanto ao modelo estatal, relaciona algumas características que correspondem a uma constituição "ideal”, as quais assim podem ser sintetizadas:

a) inicialmente, uma das características corresponde ao momento fundacional (constitutional moment), que sinaliza um marco de transformação no findar da Segunda Grande Guerra, o qual acena para uma ruptura dos tradicionais conceitos de soberania e bilateralismo; b) num outro aspecto, a característica de propor um programa constitucional (constitutional program) de uma nova ordem mundial, objetivando a paz, a segurança e as relações amistosas entre as nações; c) outra importante menção é a denominação, pois diferentemente da expressão "convênio", comumente utilizada, o termo Carta (Charter) parece derivado de sua especial significação; d) por outro lado, numa alusão ao poder 
constituinte (constitutional power), como estabeleceu historicamente a constituição dos Estados Unidos de 1787 ("We the people”), a Carta enuncia em seu Preâmbulo a essência de sua origem: "We the People of United Nations"; e) o aspecto histórico (constitucional history) é relevante, principalmente por sua expressão de legitimidade por se constituir, desde 1945, em fórum natural para temas globais comuns (direitos humanos, meio ambiente, armas nucleares, descolonização, autodeterminação dos povos, etc.); f) a exemplo das constituições estatais, a Carta da ONU tem um sistema de governança (governance system) com estruturação de funções administrativas, legislativas e decisórias e até um sistema de checks and balances; g) ao definir seus membros (defines members), a Carta da ONU também seria comparada ao modelo das constituições estatais. No entanto, pretende-se que seja uma constituição da humanidade como um todo; h) uma qualidade constitucional de fundamental importância diz respeito à hierarquia normativa (hierarchy of norms), de maneira que determina a conformidade das demais normas que integram o ordenamento de uma sociedade. O Art. 103 da Carta, que enuncia a sua preponderância em relação a qualquer outro acordo ou tratado internacional, corresponderia à conclusão de que estaria reconhecida "uma ordem jurídica internacional sob as Nações Unidas"; i) a sua vigência duradora (eternity) também mereceria o rótulo de característica constitucional; j) o caráter de universalidade (universality) levaria à interpretação de que não se destina somente aos membros reconhecidos das Nações Unidas, mas sim a toda a comunidade jurídica internacional. (FASSBENDER, 2009, p. 86$115)$.

Para Fassbender (2009, p. 187), reconhecer a Carta da ONU como uma constituição pode corresponder a um "esforço para identificar e interpretar, por meio da ciência jurídica e da linguagem jurídica, a mudança estrutural profunda da ordem jurídica internacional que ocorreu a partir de 1945”. Independentemente do que o futuro reserva a essa perspectiva, Fassbender expressa sua convicção de que "será reconhecida como a mais importante contribuição do século XX para a história constitucional do mundo".

Para uma análise mais prudente em torno do objeto deste artigo, o aceno positivo ante a identificação de alguns aspectos de viés constitucional, orgânicos e materiais, merece ser confrontado com as eventuais dificuldades que possa influir no diagnóstico pretendido. De fato, alguns obstáculos podem ser constatados na observação do âmbito orgânico e funcional da Organização das Nações Unidas bem como na realização de seus fins.

No que concerne à sua essência existencial, Cassese (2005, p. 336) assevera que a ONU foi concebida na tentativa de coordenar uma sociedade anárquica de Estados egocêntricos (modelo Grociano), mas que com o tempo acabou adquirindo um perfil voltado à cooperação e à realização de valores comuns (modelo Kantiano), fato que poderia denotar 
uma dualidade e, por consequência, tornar inviável a sua consideração como constituição da comunidade internacional. A sugestão de Cassese para essa contradição seria o esforço dos Estados na consecução de princípios, valores e objetivos comuns.

Para Cohen (2002, p. 288-290), a perspectiva constitucionalista é rudimentar e serve apenas como aspiração. Uma de suas ponderações que afasta a leitura constitucionalista consiste na inexistência de uma Corte que garanta, formal e materialmente, as deliberações das Nações Unidas. De outro lado, contrariamente da realidade estatal, inexistiria separação de poderes, muito menos o sistema de freios e contrapesos, além de apresentar deficiências de accountability. Cohen refere-se também a deficiência na proteção dos direitos humanos, bem como no aspecto normativo.

Crawford (2014, p. 459) assevera que os limitados qualificativos constitucionais da Carta são devidos mais em razão da "retórica do preâmbulo, na ambição da declaração de seus propósitos e o alcance dos poderes que confere ao Conselho de Segurança e à Assembleia Geral. Para Crawford (2014, p. 460-461), a debilidade constitucional da Carta também é percebida pela inexistência da separação de poderes, bem como porque o Conselho de Segurança somente possui alguma limitação diante de eventuais discordâncias entre os membros temporários e permanentes, mas não encontra efetivo limite por nenhum controle judicial independente. Num outro aspecto, anota que é quase inexistente a previsão que garanta direitos para um Estado, individualmente considerado. Relativamente quanto à efetividade das Nações Unidas, Crawford (2014, p. 462) cita, entre outros, problemas na administração interna, na deficiência fiscal recorrente, problemas na consecução da paz, bem como na dificuldade de soluções em disputas internacional, como no caso Israel-Palestina.

Deficiências também podem ser constatadas no âmbito interno da Organização, seja no aspecto burocrático como na própria governança. Por outro lado, há bastante dificuldade na realização de medidas que diminuam as diferenças entre os países industrializados dos demais. Ademais, verifica-se a ocorrência de falhas na manutenção da paz, na segurança e nos anseios de desarmamento. No curso de sua evolução histórica, observa-se que as Nações Unidas também não lograram êxito em diversas circunstâncias, de modo a prejudicar a consecução de seus fins. A propósito, o retrocesso no período da guerra fria, o fracasso em operações de paz, limitações no que concerne à cooperação para o desenvolvimento e na unilateralidade dos Estados Unidos. Um dos fracassos sempre lembrado diz respeito ao massacre étnico em Ruanda no ano de 1994, que resultou em mais de 800.000 mortes. Diversas outras crises e atrocidades que ameaçam a paz e a segurança ocorrem sem uma intervenção mais efetiva, inclusive na atualidade, em que se assiste a divisão do mundo em contendas envolvendo o terrorismo e o radicalismo religioso, envolvendo diversas regiões do planeta, ocasionando uma série de efeitos trágicos, desde a migração de populações, mortes e 
destruição de famílias. Cassese, no entanto, adverte que essas deficiências não podem ser atribuídas necessariamente a ONU, mas sim devem ser "rastreadas até os Estados por trás dela, principalmente as grandes potências".

Mas é com relação ao Conselho de Segurança das Nações Unidas que as críticas são mais contundentes, especialmente diante da sua composição em que ocorre a preponderância dos vitoriosos da Segunda Guerra Mundial como membros permanentes (China, França, Reino Unido, Rússia e Estados Unidos da América), tendo em vista o significativo valor de seu poder pela previsão do uso da força para garantir a paz na forma dos Arts. 39 a 43 do Capítulo 7 da Carta das Nações Unidas, tanto por intermédio de sanções como por intervenção militar. Ademais, o Conselho de Segurança tem especial papel na escolha do Secretário-Geral e, em conjunto com a Assembleia Geral, na escolha de juízes para a composição da Corte Internacional de Justiça. Ressalta-se que as decisões de cunho substantivo do Conselho de Segurança são tomadas pelo voto afirmativo de nove membros, incluídos os membros permanentes, de tal maneira que pode se configurar em veto. Assim, verifica-se a indisfarçável preponderância das decisões dos membros permanentes. De tal maneira, o poder de veto (Art. 27, 3) contribui para o desequilíbrio de participação e do exercício do poder, ocasionando déficits de legitimidade democrática.

Alguns aspectos podem ser apontados para uma agenda de reforma das Nações Unidas, objetivando corrigir as deficiências comumente constatadas. Conforme Habermas (2008, p. 173-174), tais mudanças devem ser direcionadas para a adequação do Conselho de Segurança à atual situação geopolítica, de forma a corrigir as distorções de representação bem como para aumentar sua capacidade de ação. O Conselho de Segurança deveria seguir sua própria agenda, sem a interferência dos interesses nacionais. Na verdade, caberiam esforços para a legitimação e a eficácia das decisões legislativas do Conselho de Segurança e da Assembleia Geral, inclusive com o aperfeiçoamento de mecanismos de controle por organizações não governamentais. De outro lado, há necessidade de reforço financeiro na executiva da ONU, bem como na implementação de medidas que favoreçam a efetividade de suas resoluções.

Dessa forma, o esboço acima apresentado permite concluir que a perspectiva que confere à Carta das Nações Unidas a configuração de constituição da comunidade internacional não encontra uma resposta aperfeiçoada, embora o peso das deficiências e das dificuldades apontadas parece recomendar cautela ante o perigo das conclusões precipitadas. De todo modo, não se pode dispensar que sejam empreendidos esforços para as necessárias mudanças na Organização das Nações Unidas que o próprio desenvolvimento e a evolução da sociedade mundial exige, mesmo compreendendo tratar-se de tarefa árdua e repleta de 
complexidades. Contudo, as conquistas, a universal abrangência e a relevância dos serviços das Nações Unidas reforçam a sua legitimação com um destacado locus de convergência para a realização dos valores de paz para toda a humanidade.

\section{CONSIDERAÇÕES FINAIS}

Propôs-se, como objeto central da investigação, examinar a dimensão da concepção teórica que erige a Carta das Nações Unidas como uma "constituição da comunidade internacional". Corresponderia esta perspectiva a uma real possibilidade ou não passaria de mera especulação retórica sustentada por um pensamento idealista?

Como se pode perceber, a complexidade que acompanha a tarefa anunciada não admite conclusões simplistas ou precipitadas, mas os argumentos esboçados ao longo do texto permitem algumas considerações que, embora com caráter provisório, podem indicar rumos para os quais a reflexão sobre a temática possa ser ampliada e aperfeiçoada.

A abordagem insere-se no campo de investigação própria do constitucionalismo global (internacional), em que se identifica e se sustenta a utilização de princípios de matriz tipicamente constitucional no ambiente jurídico global (internacional). A variada literatura acadêmica sobre o tema revela um complexo e multifacetado cenário de abordagens, razão pela qual foi necessário apresentar, com base em Schwöbel (2011), uma sintética categorização do debate acadêmico ("constitucionalismo social", "constitucionalismo institucional", "constitucionalismo normativo", "constitucionalismo analógico"), ressaltando que não se tratam de abordagens fechadas, pois interagem e se sobrepõem (seção 1).

Sem embargo, para os fins deste estudo, pode-se estabelecer que o debate comporta duas vertentes gerais. Numa delas, a constitucionalização global ocorre numa série de processos diferenciados, de viés pluralístico; noutra, que engloba o problema da Carta da ONU, a constitucionalização global ocorre por intermédio de uma forma abrangente e unitária.

Considerando o objeto do artigo, que se situa na vertente unitária do constitucionalismo global, a análise reclama que se considere a ideia de uma "comunidade internacional", o que implicaria também no compartilhamento de valores comuns (seção 2). Nesse sentido, em face da intensificação da sociedade mundial e da globalização, pode ser reconhecido um processo de aproximação e interdependência, ainda que débil, dos diversos atores jurídicos internacionais, inclusive os indivíduos, em torno de alguns temas de pertinência comum. O processo de universalização dos direitos humanos, pelo menos um núcleo fundamental deles, poderia servir como ponte para o diálogo e para a interação. Acredita-se que a ideia de comunidade internacional é importante para o enfrentamento das 
questões comuns da humanidade, tais como o problema ambiental, as intervenções humanitárias, o terrorismo e a criminalidade internacional, o combate à miséria, a economia e o sistema financeiro internacional, a saúde, as comunicações, etc. Nesse quadro, o papel das Nações Unidas se mostra fundamental.

Pelo menos simbolicamente, os Tratados de Paz de Westfália (1648), o Congresso de Viena (1815), o Tratado de Versalhes (1919), o Convênio da Liga das Nações (1949) e a Carta das Nações Unidas (1945) receberam a designação de "momentos constitucionais", ante a sua especial significação para o desenvolvimento do direito internacional. Notadamente a Carta das Nações Unidas ocupa uma posição destacada na esfera internacional e representa, de fato, "alguma coisa a mais do que um tratado", mas sua escassa virtude constitucional não lhe legitima como uma "constituição da comunidade internacional" (seção 3), tendo em vista a realidade das relações internacionais contemporâneas (VIVIANI, 2014).

Mesmo diante do débil caráter constitucional de sua Carta das Nações Unidas, a realidade contemporânea sugere reflexões e atitudes que busquem o aperfeiçoamento dessa notável instituição, tendo em vista as deficiências comumente apontadas, necessárias diante de sua elevada missão na consecução da paz, da segurança e dos valores comuns para a convivência da sociedade mundial.

É inevitável, no âmbito do constitucionalismo global, confrontar o ordenamento jurídico internacional com a tradição própria do constitucionalismo, conforme gradual e historicamente aperfeiçoado no âmbito dos Estados, principalmente a partir do século XVII. Forjam-se, nessa esteira, os alicerces básicos da ideia de constituição: organização e limitação do poder político, separação de poderes, mecanismos de controle (check and balances), e garantia de direitos fundamentais. Sem estas categorias mínimas, não parece viável reconhecer, pelo menos no sentido forte e estrito do termo, a existência de uma constituição.

Além da carência de suficientes características do constitucionalismo e das deficiências da Organização das Nações Unidas, que prejudicam a qualidade constitucional da Carta, os estudos especializados acrescentam outros desafios no âmbito do constitucionalismo global, que merecem ser considerados, tais como a pertinência simbólica (sentimento de pertencer a um "povo constitucional"), o problema da fragmentação do direito internacional (proliferação de regimes especializados), a gama de divisões na sociedade global, com diferenciações econômicas, culturais, religiosas, etc., as constantes situações beligerantes, a desigualdade quanto ao desenvolvimento econômico entre os povos, os déficits de democracia e legitimidade, a falta de efetivação dos direitos humanos, a preponderância de superpotências, especialmente dos Estados Unidos da América, dentre outros fatores (VIVIANI, 2014). 
O cenário desafiador, entretanto, não é suficiente para impedir o desenvolvimento do constitucionalismo global, que parece ser inevitável ante as relações interdependentes e valores comuns que transbordam dos estritos limites dos Estados. Portanto, entende-se que o constitucionalismo global corresponde a um processo contínuo, ainda numa parcial e incompleta realidade. Reclama o enfrentamento das questões que envolvam o problema da existência de subsistemas diversos, da pretensão de unidade, da hierarquia, e dos demais aspectos de uma sociedade pluralista.

Dessa maneira, compreende-se o constitucionalismo global não na sua perspectiva ampla e unitária, como aquele baseado na Carta da ONU, mas por intermédio dos sistemas diferenciados e de suas interações, nos âmbitos doméstico, regional e global.

Compreendendo que o tema se reveste de importância e de potencial crítico, esperase, por fim, que os argumentos disseminados ao longo do artigo possam estimular proveitosos debates em torno da constitucionalização na esfera internacional.

\section{REFERÊNCIAS}

CASSESE, Antonio. For an Enhaced Role of Jus Cogens. In: CASSESE, Antonio (Ed.). Realizing Utopia: the future of International Law. Oxford: Oxford University Press, 2012.

CASSESE, Antonio. International Law. 2. ed. Oxford: Oxford University Press, 2005.

COHEN, Jean L. Globalization and Sovereignty: rethinking, legality, legitimacy, and constitutionalism. Cambridge: Cambridge University Press, 2002.

CRAWFORD, James. Chance, Order, Change: the course of international law (General Course on Public International Law). Hague: Hague Academy of International Law, 2014.

DE WET, Erika. The International Constitutional Order. International and Comparative Law Quarterly, v. 55, p. 51-76, 2006.

DUPUY, Pierre-Marie. The Constitutional Dimension of the Charter of the United Nations Revisited. BOGDANDY, Armin von; WOLFRUM, Rüdiger (Editors). Max Planck Yearbook of United Nations Law. v. 1, p. 1-33, 1997.

FASSBENDER, Bardo. The United Nations Charter as the Constitution of the International Community. Leiden (Netherlands): Martinus Nijhoff, 2009.

GRIMM, Dieter. The Achievement of Constitutionalism and its Prospects in a Changed World. In: DOBNER, Petra; LOUGHLIN, Martin (Edits.). The Twilight of Constitutionalism? Oxford: Oxford University Press, 2012. p. 3-32.

HABERMAS, Jürgen. The Divided West. Edited and translated by Ciaran Cronin. Cambridge: Polity Press, 2008. Título original: Der gespaltene Western. 
KIM, Samuel S. In Search of Global Constitutionalism. In: FALK, Richard A.; JOHANSEN, Robert C.; KIM, Samuel S. The Constitutional Foundation of World Peace. Albany: State University of New York Press, 1993. p. 55-81.

KLEINLEIN, Thomas. Alfred Verdross as a Founding Father of International Constitutionalism? In: Goettingen Journal of International Law, v. 4, n. 2, 2012. p. 385416.

KOSKENNIEMI, Martti. From Apology to Utopia: the structure of international legal argument. Cambridge: Cambridge University Press, 2005.

MACDONALD, Ronald St. John. The International Community as a Legal Community. In: MACDONALD, Ronald St. John; JOHNSON, Douglas M. (eds). Towards World Constitutionalism: issues in the legal ordering of the world community. Leiden: Brill, 2005.

PETERS, Anne. Compensatory Constitutionalism: The Function and Potential of Fundamental Norms and Structures. In: Leiden Journal of International Law, n. 19, 2006.

PETERS, Anne. Constitucionalismo compensatório: las funciones y el potencial de las normas y estructuras internacionales. In: PETERS, Anne; AZNAR, Mariano J.; GUTIÉRREZ, Ignacio. La Constitucionalización de La Comunidad Internacional. Tradução de Mariano J. Aznar Gómez e Alejandra Laura Videla. Valência: Tirant lo Blanch, 2010.

PETERS, Anne. Constitucionalismo Compensatório: las funciones y el potencial de las normas y estructuras internacionales. In: PETERS, Anne; AZNAR, Mariano J.; GUTIÉRREZ, Ignacio. La Constitucionalización de La Comunidad Internacional. Tradução de Mariano J. Aznar Gómez e Alejandra Laura Videla. Valência: Tirant lo Blanch, 2010. p. 207-261.

PETERS, Anne. Constitutional Fragments: On the Interaction of Constitutionalization and Fragmentation in International Law. CGC Working Paper n. 2. University of St Andrews. Centre for Global Constitutionalism: April, 2015. p. 1-42.

PETERS, Anne. The Merits of Global Constitutionalism. Indiana Journal of Global Legal Studies, v. 16, 2009.

SCHWÖBEL, Christine E. J. Global Constitutionalism in International Legal Perspective. Leiden/Boston: Martinus Nijhoff Publishers, 2011.

TOMUSCHAT, Christian. La Comunidad Internacional (Die Internationale Gemeinschaft). In: PETERS, Anne; AZNAR, Mariano J.; GUTIÉRREZ, Ignacio. La Constitucionalización de La Comunidad Internacional. Tradução de Mariano J. Aznar Gómez e Alejandra Laura Videla. Valência: Tirant lo Blanch, 2010. p. 93-119.

TOMUSCHAT, Christian (Ed.). The United Nations at Age Fifty: a legal perspective. Hague (Netherlands): Kluwer Law International, 1995.

TÖNNIES, Ferdinand. Community and Society. Tradução e edição de Charles P. Loomis. Mineola, New York: Dover Publications, Inc., 2002. Título original: Gemeinschaft und Gesellschaft.

VERDROSS, Alfred. Die Verfassung der Völkerechtsgemeinschaft (The Constitution of the International Legal Community). Wien/Berlin: Springer, 1926. 
VIVIANI, Maury Roberto. Constitucionalismo Global: crítica em face da realidade das relações internacionais no cenário de uma nova ordem mundial. Rio de Janeiro: Lumen Juris, 2014.

WELLER, Marc. The Struggle for an International Constitutional Order. In: ARMSTRONG, David (Edit.). Routledge Handbook of International Law. London and New York: Routledge/Taylor \& Francis Group, 2009. 